\title{
The Impact of Coronavirus on Staff Nurses' Feeling While Giving Direct Care to COVID-19 Patients in Various COVID Facilities
}

\author{
Sanaa M. Taghaddom ${ }^{1}$, Heyam M. A. R. B. Alrashidi², Hoda Diab Mohamed1, \\ Marthal Nandhini Johnson ${ }^{1}$
}

${ }^{1}$ Nursing Services Administration, Kuwait City, Kuwait

${ }^{2}$ Mubarak Al Kabeer Hospital, Jabriya, Kuwait

Email:*s_takadoom@hotmail.com

How to cite this paper: Taghaddom, S.M., Alrashidi, H.M.A.R.B., Mohamed, H.D. and Johnson, M.N. (2020) The Impact of Coronavirus on Staff Nurses' Feeling While Giving Direct Care to COVID-19 Patients in Various COVID Facilities. Open Journal of Nursing, 10, 873-889.

https://doi.org/10.4236/ojn.2020.109060

Received: August 12, 2020

Accepted: September 19, 2020

Published: September 22, 2020

Copyright $\odot 2020$ by author(s) and Scientific Research Publishing Inc. This work is licensed under the Creative Commons Attribution-NonCommercial International License (CC BY-NC 4.0). http://creativecommons.org/licenses/by-nc/4.0/ cC) (i) (8) Open Access

\begin{abstract}
Background: Nurses are very important frontline health care professionals as they spend more time with patients than other professionals. This is even more so at this critical time of the COVID-19 pandemic. The nursing profession is facing great challenges in coping with the pandemic as they are more vulnerable to exposure and infection with the disease. Kuwait is not spared from the global pandemic which has put the health sector under immense pressure. Because COVID-19 is highly transmissible and deadly, it poses a huge health risk to nurses and has a huge impact on their cognitive, emotional, behavioural and physical dimensions. Aim: The study aims to explore the positive and negative emotions and feelings of staff nurses while giving care to COVID-19 patients. Materials and Methods: A descriptive cross-sectional study was carried out. 300 nurses from different general hospitals, field hospitals, and quarantine facilities in Kuwait participated in the study. A questionnaire was used to collect the data. Results: The findings show that for the cognitive evaluation, $72 \%$ were moderately affected, for the emotional evaluation $51.3 \%$ and $44 \%$ were moderately and mildly affected respectively, for the behavioural evaluation, $66.7 \%$ were severely affected, and for the physical evaluation, $43.3 \%$ and $31.7 \%$ were moderately and severely affected respectively. Prolonged working hours has a highly significant negative correlation to emotional $(r-0.165)$, behavioral $(r-0.177)$ and physical $(r-0.155)$ dimension of the nurses at 0.01 level using Spearman's correlation. Conclusion: The study concluded that the COVID-19 pandemic has affected the psychophysical dimensions of staff nurses.
\end{abstract}




\section{Keywords}

COVID-19 Pandemic, Psychophysical Dimensions, Positive and Negative Emotions, Positive and Negative Feeling, Field Hospital, Quarantine Facility

\section{Introduction}

According to the World Health Organization (WHO), infectious diseases are the third leading cause of death in the world [1] [2]. Emerging global pandemics pose a great risk to individuals and communities. The current and most significant one in recent times is the COVID-19 pandemic. Due to its rapid spread, virulence, and lethality in severe cases, and due to the fact that it has no known cure, it poses a huge threat to human life and health, and also has an enormous impact on the mental health of the general public, causing people different degrees of emotional problems [3] [4] [5] [6]. COVID-19 has also become a major cause of stress for individuals and social public groups [3] [7].

Globally, the COVID-19 pandemic has become an emergency that has presented the entire medical system with major and serious challenges [8] [9]. As of June 16, 2020, there were $8,137,110$ confirmed cases of COVID-19 worldwide, with 439,577 deaths [10].

The status of COVID-19 in the Gulf Cooperation Council (GCC) countries (Saudi Arabia, Oman, Kuwait, United Arab Emirates (UAE), Qatar, and Bahrain) as of $18^{\text {th }}$ May 2020 is widely varied" [11] [12] [13]. As of $18^{\text {th }}$ June 2020, in Kuwait, 30,644 confirmed cases and 244 deaths have been reported, causing immense stress to the Kuwaiti health care system [14].

The first confirmed COVID-19 case in Kuwait was announced on $24^{\text {th }}$ February 2020. As of $7^{\text {th }}$ June 2020, there were 31,848 confirmed cases of COVID-19, with 20,205 recoveries and 264 deaths [14]. About 1480 staff nurses turned out to be COVID-19 positive by $18^{\text {th }}$ June 2020 [15].

Historically, during sudden natural disasters and infectious disease outbreaks, nurses gave up their own needs and actively participated in efforts against the epidemics, making selfless contributions out of their moral obligation and professional responsibility [16] [17]. In each country, regardless of their socio-economic development, nursing is considered to be a dedicated profession in the prevention of diseases and alleviation of suffering during and after a treatment of any disease, including COVID-19 [18] [19].

As frontline professionals, nurses, being vital service providers, stay with patients suffering from complex diseases which require hospitalization and intensive critical care, as seen in COVID-19 [20] [21] [22] [23]. During the peak of the COVID-19 pandemic, the number of patients that required ventilator support was much higher than the available bed capacity in the intensive care units (ICU) [18] [24]. So, general hospitals were changed to critical care hospitals and general beds were swiftly transformed to ICU beds. This increased the demand 
of staffing, requiring staff training in critical areas and their transfer to provide service in different hospitals [18] [25] [26].

Nurses are therefore experiencing pressure, fear, exhaustion, isolation, and persistent emotional trauma during the COVID-19 pandemic [27] [28]. This ongoing stress and trauma impact on their mental health, safety, and ability to provide the best possible care [27]. Fighting against specific infectious diseases is a serious challenge for medical staff, especially for nurses, who are at risk of death at any time. This is worsened by stressful work, sleep deprivation, less freedom, heavy responsibility, and an expectation of high degree of cooperation [3] [29] [30] [31] [32] [33]. Nurses serve as an important force in the fight against the epidemic, and they are under the highest pressure of all medical workers [34] [35] [36]. Sabah (2020) reported the case of a 34-year old Italian nurse who was working on the frontline seeing the suffering of the coronavirus disease patients at the intensive care unit of a hospital in Lombardy, the worst-affected region of Italy. She committed suicide after testing positive for coronavirus [18] [37].

$\mathrm{Li}$ and colleagues reported that the prevalence of depression and anxiety was $21.3 \%$ and $19.0 \%$, respectively among public health care workers (HCWs) in the frontline during the COVID-19 epidemic [38] [39]. A higher risk of depression, anxiety, insomnia and distress were associated with direct diagnosis, treatment, and care of COVID-19 patients among frontline health care workers [22] [34] [38] [40] [41] [42]. There were reports that the nurses were anxious about their safety and the psychological effects from mortality reports related to COVID-19 infection [34] [38] [43] [44] [45].

Meanwhile, numerous studies indicate that frequent long shifts in hospitals could compromise patient outcomes, quality of care, and safety, which lead to increased errors and even mortality [46]-[53]. Nurses who reported chronic fatigue perceived they were less alert and less able to concentrate when providing patient care, and have less effective communication [29] [54]. Nurses reported having made medication errors when they rendered more than 40 hours of duty per week or when they work 4 hours more as overtime [54] [55]. At times of crisis, nurses hold their physiological and safety needs as priorities, such as the need for adequate food, shelter, rest, sleep and safety [56] [57]. When nurses are not given enough time to recover, tiredness and exhaustion mount up and when they become chronic in nature, they adversely affect the work performance and nursing care quality [54] [58].

In 2011, Barker and Nussbaum revealed that work performance deteriorates during the last hours of working shifts [54] [59]. Due to the demands of work, nurses encounter non-standard work schedules, long duty hours, and diurnal rhythm adjustments due to night shifts, resulting in unavoidable fatigue and decrease in nursing performance [46] [54] [60] [61] [62]. On $23^{\text {rd }}$ of June 2020, Kuwait Nurses Association announced that infection rate of COVID-19 will constitute a burden on nurses, especially those working in new field hospitals, quarantine centers and hotels [63]. The close contact with COVID-19 patients 
has affected many nurses, and many could not be sent home because of the shortage of staffing. Many organizations asked their health workers who are treating COVID-19 patients to continue working with them until they show symptoms of the disease, in order to recover the staffing needs [18] [64].

Nurses reported having physical exhaustion and emotional stress when caring for overwhelming number of acutely ill COVID-19 patients of all ages who might have the tendency to deteriorate quickly [18] [34] [65] [66] [67].

The fundamental role of nursing is creating collaboration and effective teamwork, especially during the critical stages of mitigation and in response to the escalation of the COVID-19 cases. Nurses play a pivotal role in preparation, management and mitigation of infectious diseases such as COVID-19. Therefore nurses should be included in a developing strategic plan at the national level [18].

In this section, we have discussed about the impact of the COVID-19 pandemic on staff nurses working in COVID-19 units. Many studies have highlighted the effects of epidemics on psychological and physical dimensions of staff nurses which have greatly affected their emotions and feelings. However, at present, there are no studies conducted on the psychophysical dimensions of staff nurses while giving direct care to COVID-19 patients in Kuwait [3] [4] [16] [18] [22] [34] [40] [42] [56] [62].

The emotions and job satisfaction of staff nurses are worthy of attention as they are at the frontline during the COVID-19 pandemic. So, the Nursing Services Administration, Ministry of Health, Kuwait, recognizes the necessity of addressing the experience of nurses during the COVID-19 pandemic-related workload, change in their workplace and their level of stress.

\section{Methodology}

\subsection{Study Setting}

The study was conducted in three general hospitals (Al-Jahra, Al-Adan and Farwaniya) with an average bed capacity of 700 - 800; one general teaching hospital (Mubarak Al Kabeer) with 1231 bed capacity; three field hospitals (Mishref, Jleeb Al Shouyoukh and Al-Tadamon Club) with a capacity of $200-600$ beds and Mishref quarantine facility with 614 beds. Each general and teaching hospital added 60 - 200 beds for COVID-19 cases along with the existing bed capacity. The study subjects were nurses working in the ICU, wards, quarantine units, and the casualty. This descriptive cross-sectional study was conducted between April and June 2020. It was difficult to conduct physical interviews because of the nature of work of nurses in COVID units, so a questionnaire was used instead.

\subsection{Objective}

The objective of the study was to explore the positive and negative emotions and feelings of staff nurses while giving care to COVID-19 patients. 


\subsection{Data Collection Tool}

Based on literature review and suggestions of experts, a structured and semistructured questionnaire was developed. It consisted of three parts. Section 1 included socio-demographic variables like age, gender, qualification, nationality, marital status, children, living condition, years of experience in Kuwait, place of work, experience in COVID-19 unit, and working hours per week. Section 2 is structured, and consists of 33 questions to measure nurse's perceptions and feelings while providing care for patients with COVID-19 and the questions are spread over various psychophysical dimensions like cognitive, emotional, behavioural and physical perspectives, with 4-points Likert type Scale. The score "4" stands for "never" and score "1" stands for "Very Often". The overall minimum score is 33 and the maximum score is 132 . Based on the obtained scores, the staff nurses were classified as mildly affected $(75 \%-100 \%)$, moderately affected (50\% - 75\%) and severely affected (25\% - 50\%). Section 3 is a semi-structured questionnaire consisting of 6 questions based on the experience, coping strategies, and preparedness in dealing with COVID-19 patients of the nurses.

\subsection{Ethical Considerations}

Ethical approval was obtained after six weeks of submitting the study proposal to the Standing Committee for Coordination of Health and Medical Research, Ministry of Health, Kuwait. The approval copy was distributed to the hospitals where the study was conducted. The participants were included in the study after obtaining the consent (either in English or Arabic).

\subsection{Participants}

All the staff nurses working in COVID-19 units (COVID ICU, COVID Casualty, COVID field hospitals and COVID quarantine facility) were potential candidates for the study. Purposive sampling was applied to select the nurses. 300 nurses were chosen to participate in the study, of which 109 were males and 191 were females.

Inclusion Criteria: Staff nurses who are working in COVID-19 units and providing direct care to confirmed COVID-19 patients who were willing to participate in the study and were present during the time of data collection were included.

Exclusion Criteria: Staff nurses who are not willing to participate in the study and rotation staff nurses working in COVID units were excluded.

\subsection{Pilot Testing}

Pilot study was conducted in Mishref Field Hospital on 10 participants after receiving the ethical approval from the Standing committee for Coordination of Health and Medical Research, Ministry of Health, Kuwait.

\subsection{Data Collection}

The primary investigator explained the study and its modalities to the co-inves- 
tigators (Assistant Director of Nursing and Head Nurses in COVID-19 units). The purpose of the study and the questionnaire were explained by the co-investigators to the participants who were asked to send back the questionnaire electronically. The data collection period was from 24th May 2020 to 4th June 2020.

\subsection{Data Analysis}

In this study, the data was analysed using IBM SPSS Statistics Version 21. The plan for data analysis included both descriptive and inferential statistics.

Frequencies and percentages were used to analyse the demographic features of staff, the psychophysical dimensions and semi-structured questions. The Spearman rank order correlation was used to find relationship between the psychophysical dimensions and the demographic variables among the staff nurses.

\section{Results}

\subsection{Demographic Characteristics of Participants}

Table 1 shows that $60.7 \%$ of nurses have BSN qualification. Nursing Services Administration hires preferably BSN and higher qualification as per $\mathrm{MOH}$ recruitment criteria for candidates outside Kuwait. Most of the participants (75.7\%) belonged to the age group of 31 - 40 years old. A large part of staff nurses (70.3\%) has 1 - 10 years of clinical experience in Kuwait. 55\% of participants have been working for more than 6 weeks and 45\% for 2 - 6 weeks in COVID units. Nurses from other clinical areas, clinics and school health were deployed in field hospitals, COVID-19 units and quarantine facility from early March 2020 to meet the staffing needs. $63.7 \%$ were females and $36.3 \%$ were males. $94.3 \%$ were married. $87.7 \%$ had children.

\subsection{Effect of COVID-19 on Psychophysical Dimensions of Staff Nurses}

Figure 1 shows that cognitively, $72 \%$ of staff nurses were moderately affected, whereas $16.3 \%$ were severely affected while caring for COVID-19 patients. This shows the nurses' initial response when confronted with a highly contagious disease. Emotionally, $51.3 \%$ of staff nurses were moderately affected and $44 \%$ were mildly affected. This is because nurses have confidence in the timely strategies implemented by Ministry of Health to combat the pandemic. Behaviorally, $66.7 \%$ were severely affected and $32 \%$ were moderately affected because of lack of experience in dealing with the complex nature of the disease. Physically, $43.3 \%$ of the nurses were moderately affected and $31.7 \%$ were severely affected due to increase in duty hours and workload.

\subsection{Correlation between Demographic Variables and Psychophysical Dimensions}

Table 2 indicates that there is no significant correlation between cognitive di- 
mensions and the provided demographic variables. Emotional dimension has a significant positive correlation to the number of years of experience in Kuwait, $\mathrm{r}(0.146)=0.011, \mathrm{p}<0.05$, but a highly significant negative correlation with number of working hours per week, $r(-0.165)=0.004, p<0.01$. Similarly, highly a significant positive correlation was found between behavioural dimension and age and number of years of experience in Kuwait, $\mathrm{r}(-0.158)=0.006, \mathrm{p}<0.01$ and $r(-0.254)=0.000, p<0.01$ respectively. Behavioural dimension and number of working hours per week have a highly significant negative correlation, $r(-0.177)=0.002, p<0.01$. Moreover, there was a significant positive correlation

Table 1. Distribution of staff nurses according to demographic variables.

\begin{tabular}{|c|c|c|}
\hline \multirow{2}{*}{ Demographic Variables } & \multicolumn{2}{|c|}{ Frequency and Percentage $\mathbf{n}=\mathbf{3 0 0}$} \\
\hline & Frequency & Percentage (\%) \\
\hline \multicolumn{3}{|l|}{ Qualification } \\
\hline MSN & 05 & 1.7 \\
\hline BSN & 182 & 60.7 \\
\hline Diploma & 113 & 37.6 \\
\hline \multicolumn{3}{|l|}{ Age (in years) } \\
\hline $21-30$ & 18 & 6 \\
\hline $31-40$ & 227 & 75.7 \\
\hline $41-50$ & 49 & 16.3 \\
\hline$>51$ & 6 & 2 \\
\hline \multicolumn{3}{|c|}{ Number of Years of Experience in Kuwait } \\
\hline $01-10$ & 211 & 70.3 \\
\hline $11-20$ & 78 & 26 \\
\hline $21-30$ & 10 & 3.4 \\
\hline$>30$ & 1 & 0.3 \\
\hline \multicolumn{3}{|l|}{ Experience in COVID-19 unit } \\
\hline 2 - 6 weeks & 135 & 45 \\
\hline$>6$ weeks & 165 & 55 \\
\hline \multicolumn{3}{|l|}{ Gender } \\
\hline Male & 109 & 36.3 \\
\hline Female & 191 & 63.7 \\
\hline \multicolumn{3}{|l|}{ Marital status } \\
\hline Married & 283 & 94.3 \\
\hline Single & 17 & 5.7 \\
\hline \multicolumn{3}{|l|}{ Children } \\
\hline Yes & 263 & 87.7 \\
\hline No & 37 & 12.3 \\
\hline
\end{tabular}




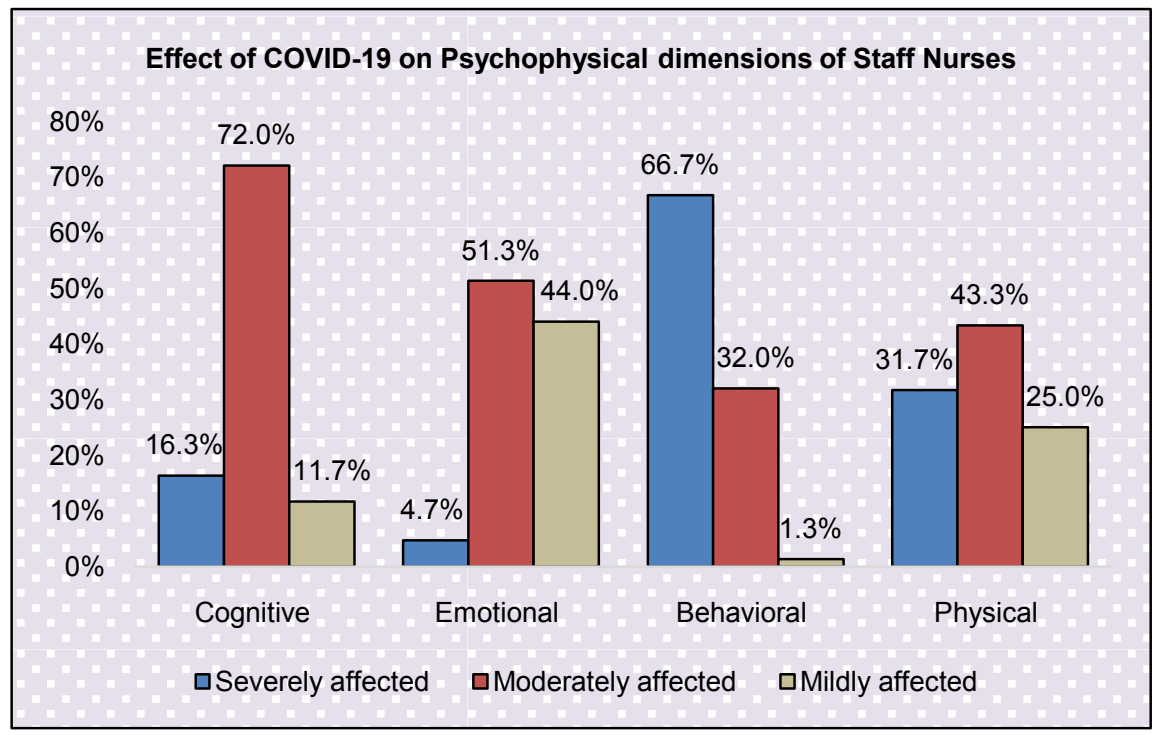

Figure 1. Effect of COVID-19 on psychophysical dimensions of staff nurses.

Table 2. Correlation between demographic variables and psychophysical dimensions. $\mathrm{n}=$ 300 .

\begin{tabular}{cccccc}
\hline \multicolumn{2}{c}{ Demographic Variables } & Cognitive & Emotional & Behavioral & Physical \\
\hline Age & Correlation Coefficient & 0.058 & 0.069 & $0.158^{* *}$ & 0.041 \\
& Sig. (2-tailed) & 0.320 & 0.234 & 0.006 & 0.478 \\
& Correlation Coefficient & 0.034 & $0.146^{*}$ & $0.254^{* *}$ & $0.133^{*}$ \\
$\begin{array}{c}\text { Number of Years of } \\
\text { Experience in Kuwait }\end{array}$ & Sig. (2-tailed) & 0.561 & 0.011 & 0.000 & 0.021 \\
$\begin{array}{c}\text { Experience in } \\
\text { COVID-19 unit }\end{array}$ & Correlation Coefficient & 0.095 & 0.048 & $0.122^{\star}$ & -0.050 \\
$\begin{array}{c}\text { Number of Working } \\
\text { Hours Per Week }\end{array}$ & Correlation Coefficient & -0.112 & $-0.165^{* *}$ & $-0.177^{* *}$ & $-0.155^{* *}$ \\
\hline
\end{tabular}

${ }^{*}$ Correlation is significant at the 0.01 level (2-tailed); ${ }^{*}$ Correlation is significant at the 0.05 level (2-tailed).

between physical dimension and the number of years of experience in Kuwait, $\mathrm{r}(0.133)=0.021, \mathrm{p}<0.05$ but a highly significant negative correlation with number of working hours per week, $\mathrm{r}(-0.155), \mathrm{p}<0.01$.

Emotional, behavioural and physical dimensions of nurses improve with the duration of experiences because of their deeper understanding about nature of work which makes them easy to adjust to the new working conditions. The prolonged duty hours decline their emotional, behavioural and physical dimensions. Behavioural dimension improves as the age and experience in COVID-19 unit increases due to level of acceptance and familiarity with COVID-19 protocols.

\section{Discussion}

The study aimed to explore the positive and negative emotions and feelings of 
nurses while giving care to COVID-19 patients in general hospitals, field hospitals and a quarantine facility in the Ministry of Health, Kuwait. The researcher studied the effect of the COVID-19 pandemic on the cognitive, emotional, behavioural and physical dimensions of staff nurses to achieve the study objective.

\section{Section 1: Demographic Characteristics of the Staff Nurses}

The demographic characteristics of the study reflect that the majority of the nursing workforce in the government sector in Kuwait is females [15]. Due to cultural considerations, female nurses are preferred. Most of the staff nurses are between 31 and 40 years old. $44 \%$ of the staff nurses working in the Ministry of Health have a bachelor's degree, $42 \%$ have diploma in nursing, $13 \%$ have nursing certificate, and $1 \%$ of the nurses have master's degree.

Section 2: Descriptive Statistics of Cognitive, Emotional, Behavioural, and Physical Dimensions

The researcher used a scale of mildly, moderately, and severely affected to explore the degree of how the participants were impacted by COVID-19 in relation to the four psychophysical dimensions. For cognitive dimension, majority of the participants were moderately affected, nearly one-fifth were severely affected, and few were mildly affected. This reflects a normal response of an individual when dealing with a new situation. In Kuwait, strategies had been formulated and implemented in the early phase. The preparedness of the facility, availability of the protocol, and knowledge about the nature of the disease may have contributed greatly to the considerable level of adaptation shown by the staff nurses while caring for COVID-19 patients. This finding adds evidence that nurses can adjust their cognitive rationality to adapt to epidemics as previously stated by Niuniu et al and Mishra et al. [16] [68].

On emotional dimension, more than half of the nurses were moderately affected, almost half of them were mildly affected, while very few were severely affected. Though the pandemic is challenging, harmful, and poses a threat to the health of staff nurses, the result obtained in this study is in contrast with the result from previous studies. The existence of positive feelings and emotions in our nurses could be attributed to their trust in the system in terms of safety, infection control measures, and training, as well as their related professional experiences.

In the behavioural dimension, most of the participants felt that they have been severely affected. Majority of them reported that they were finding it difficult to follow and practice the COVID protocols very often. Some participants also reported that they had difficulty in practicing nursing care. Some of them cried at the workplace due to increased workload while some isolated themselves. A research done during the MERS-CoV pandemic revealed that some nurses had to move to work at other units, such as temporary quarantine centres, hospital entrance gates, or airborne isolation rooms, and they reported experiencing burnouts as they faced the deteriorating situation and worked without knowing when the pandemic would stop [34]. Hospitals and COVID facilities were over- 
whelmed with the growing number of patients. Therefore, redistribution of nurses took place in many health care settings in Kuwait. This may have led to the negative effect of the pandemic on the behavioural dimension of the nurses.

On physical dimension, about half of the participants were moderately affected, while about one-third were severely affected. Usual duty hours in Kuwait are 42 - 48 hours per week. Due to the spike of COVID cases in the country, general hospitals extended wards to cater for COVID-19 patients. Working hours of most nurses from field hospitals and the quarantine facility increased to between 60 to 84 hours per week. Facing a new disease with high transmissibility, working in an entirely new environment, and working for prolonged working hours could have led to the majority of nurses being moderately and severely affected as they felt physical symptoms such as headache, back pain, increase in heart rate, feeling weak, physical problems due to wearing of PPE for long hours, and others.

Section 3: Inferential Statistics of Demographic and Psychophysical Dimensions

In this study, the cognitive dimension had no significant correlation with age, experience in Kuwait, experience in COVID-19, and number of working hours per week.

The emotional dimension has a significant positive correlation with the number of years of experience in Kuwait which implies that as the years of experience increase, the emotional response becomes better. This could be attributed to familiarity and adjustment to the work setting and the environment which could reduce negative emotions and feelings. Meanwhile, the emotional dimension has a highly significant negative correlation to number of working hours per week which means that more working hours could negatively affect emotions.

The behavioural dimension has a highly significant positive correlation to age, number of years of experience in Kuwait and with significant positive correlation to duration of experience in COVID unit, and a highly significant negative correlation to number of working hours per week. As the age, years of experience, experience in COVID unit progresses, there is an expected increase in positive behaviour which could be as a result of increased level of maturity, knowledge and experience, information, adaptation and coping which develop over time. On the other hand, increase in working hours would deteriorate the staff nurses' behaviour. Similar results were reported in a study where nurses' acute and chronic fatigue levels were significantly associated with nursing performance in physical and mental care activities [54].

The physical dimension has significant positive correlation to the number of years of experience. which implies that the physical level increases while the years of experience increase. This could be attributed to the efficiency of nurses which develops over time. However, the physical dimension has a highly significant negative correlation with the number of working hours per week, implying that the more duty hours they rendered, the lesser their physical level became. 


\section{Section 4: Descriptive Statistics of Open-Ended Questionnaire}

Six open-ended questions were asked to help the nurses to describe their experiences at the workplace while giving care to COVID-19 patients. The study revealed that majority of the participants felt negative psychological experience such as feeling bad, worried, and depressed by the compromised quality of work, the long duty hours, and the increase in workload. This is consistent with a study done in China by Qian Liu, et al. (2020) which reports that health care providers experienced fear of infection due to the contagious nature of the virus, unknown transmission modes, close contact with patients, and infections happening to their colleagues [22]. The physical exhaustion and health threat of the pandemic have led to many negative psychological experiences among nurses.

The majority of staff nurses responded that they were trying to cope with the current situation by adapting to new workplace, personnel, protocols, etc. Our result is in accordance with a study which reports that pressure of the epidemic may prompt nurses to use their medical and psychological knowledge to actively or passively make psychological adjustments [16] [69].

Most of the participants responded that the work setting is prepared and has adequate PPE and supplies. The COVID-19 facilities in Kuwait were equipped with necessary supplies at the earliest instance. Meanwhile, almost one-third responded that the work setting was yet to be equipped. A related study showed that failure to protect nursing staff adequately is causing anger and frustration, making them feel unsafe at work while risking their own health, and making them fearful of transmitting the infection to their families [56] [70] [71] [72] [73] [74].

Majority of the participants stated that they received adequate training because they were given adequate education in different areas such as ICU and casualty care at an early phase. The result of our study contrasts with a study conducted in Italy which revealed that inadequate education since the beginning of the outbreak caused huge pressure on the Italian nurses and decreased their capability for caring [18] [75].

In this study, almost all of the participants received support from a COVID team which depicts that there is strong cohesiveness and teamwork among the health care workers. This can be attributed to proper planning and implementation of measures in the health sector in response to the pandemic.

Finally, the study reveals that almost a quarter of the participants had concerns regarding long duty hours and increase in workload. More than one-tenth had concerns regarding housekeeping and maintenance at the workplace and $2 \%$ responded that they have fear of going home because they might transfer the disease to their family members.

\section{Limitations}

This study had some limitations. The researcher was unable to conduct focus group interviews because of the risk of cross-infection due to the nature of the 
COVID-19 disease. In addition, this study was a short-term study. Long-term studies on the experiences of staff nurses caring for COVID-19 patients should be explored in the future.

\section{Recommendations}

The study results can be utilized to improve health care workplaces to avoid negative feelings and emotions among workers. A research should also be conducted on the effect of administrative and supervisory support on staff during the pandemic. A large-scale study can be carried out on the psychological experience of nurses during crisis utilizing a different standardized tool, and this can be expanded to other health care professionals. Moreover, the impact of caring the behaviour of nurses during the pandemic should be investigated further to aid the nursing service administration to formulate guidelines for in-service education.

\section{Conclusion}

This study shows that cognitive dimension of majority of the nurses caring for COVID-19 patients were moderately affected. Their emotional dimension revealed that $51.3 \%$ and $44 \%$ were moderately and mildly affected, respectively. Behaviourally, majority were severely affected. On physical dimension, 43.3\% and $31.7 \%$ were moderately and severely affected, respectively. Prolonged working hours negatively affected their emotional, behavioural and physical dimensions.

\section{Acknowledgements}

The authors would like to thank the Ministry of Health, Kuwait, for granting permission and providing timely support to completing the study.

\section{Conflict of Interest}

The authors declare no conflicts of interest regarding the publication of this paper.

\section{References}

[1] Corless, I.B., Nardi, D., Milstead, J.A., Larson, E., Nokes, K.M., Orsega, S., et al. (2018) Expanding Nursing's Role in Responding to Global Pandemics 5/14/2018. American Academy of Nursing on Policy, 66, 412-415. https://doi.org/10.1016/j.outlook.2018.06.003

[2] WHO (2017) The Top 10 Causes of Death. WHO, Geneva.

[3] Huang, L., Xu, F.M. and Liu, H.R. (2020) Emotional Responses and Coping Strategies of Nurses and Nursing College Students during COVID-19 Outbreak. medRxiv. https://doi.org/10.1101/2020.03.05.20031898

[4] Gao, J.L., Zheng, P.P., Jia, Y.N., et al. (2020) Mental Health Problems and Social Media Exposure during COVID-19 Outbreak. https://ssrn.com/abstract=3541120 https://doi.org/10.2139/ssrn.3541120 
[5] Chiu, H.F.K, Lam, L.C.W. and Chiu, E. (2003) SARS and Psychogeriatric-Perspective and Lessons from Hong Kong. International Journal of Geriatric Psychiatry, 18, 871873. https://doi.org/10.1002/gps.1003

[6] Leung, P.C. and Ooi, E.E. (2003) SARS War: Combating the Disease. World Scientific, New Jersey. https://doi.org/10.1142/5323

[7] Zhang, L.J., Lu, P.J. and Gao, Y.X. (2004) A Study on the Emotional and Behavioral Experiences of Nursing Students during the SARS Epidemic. Journal of Nurses Training, 19, 601-603. https://www.medrxiv.org/content/10.1101/2020.03.05.20031898v1.full.pdf

[8] World Health Organization (WHO) Director-General's Remarks at the Media Briefing on 2019-nCoV on 11 February 2020.

https://www.who.int/dg/speeches/detail/who-director-general-s-remarks-at-the-me dia-briefing-on-2019-ncov-on-11-february-2020

[9] World Health Organization (WHO) Director-General's Opening Remarks at the Media Briefing on COVID-19.

https://www.who.int/dg/speeches/detail/who-director-general-s-opening-remarks-a t-the-media-briefing-on-covid-19---11-march-2020

[10] World Meters. COVID-19 Coronavirus Outbreak. https://www.worldometers.info/coronavirus/

[11] Alandijany, T.A., Faizo, A.A. and Esam, A.I. (2020) Coronavirus Disease of 2019 (COVID-19) in the Gulf Cooperation Council (GCC) Countries: Current Status and Management Practices. Journal of Infection and Public Health, 13, 839-842. https://doi.org/10.1016/j.jiph.2020.05.020

[12] WHO-EMRO. World Health Organization Eastern Mediterranean Regional Office (WHO-EMRO). https://twitter.com/WHOEMRO/status/1231987263220912128?s=20.24

[13] World Health Organization (WHO). WHO Coronavirus Disease (COVID-19) Dashboard. https://who.sprinklr.com

[14] Wikipedia. https://en.wikipedia.org/wiki/COVID-19 pandemic in Kuwait

[15] Central Statistical Bureau, Kuwait. https://www.csb.gov.kw/Pages/Statistics en?ID=13\&ParentCatID=\%201

[16] Niuniu, S., Luoqun, W., Suling, S., Dandan, J., Runluo, S., Lili, M., et al. (2020) A Qualitative Study on the Psychological Experience of Caregivers of COVID-19 Patients. Americal Journal of Infection Control, 48, 592-598. https://doi.org/10.1016/j.ajic.2020.03.018

[17] Aliakbar, F.I., Hammad, K. and Bahrami, M. (2015) Ethical and Legal Challenges Associated with Disaster Nursing. Nursing Ethics, 22, 493-503. https://doi.org/10.1177/0969733014534877

[18] Buheji, M. and Buhaid, N. (2020) Nursing Human Factor during COVID-19 Pandemic. International Journal of Nursing Science, 10, 12-24. https://doi.org/10.5923/j.nursing.20201001.02

[19] WHO (2020) Clinical Management of Severe Acute Respiratory Infection When COVID-19 Is Suspected, World Health Organisation, Interim Guidance V 1.2. 13 March 2020.

https://www.who.int/publications-detail/clinical-management-of-severe-acute-respi ratory-infection-when-novel-coronavirus-(ncov)-infection-is-suspected/

[20] Khalid, I., Khalid, T.J., Qabajah, M.R., Barnard, A.G. and Qushmaq, I.A. (2016) Healthcare Workers Emotions, Perceived Stressors and Coping Strategies during 
MERS-CoV Outbreak. Clinical Medicine \& Research, 14, 7-14. https://doi.org/10.3121/cmr.2016.1303

[21] Simonds, A.K. and Sokol, D.K. (2009) Lives on the Line? Ethics and Practicalities of Duty of Care in Pandemics and Disasters. European Respiratory Journal, 34, 303-309. https://doi.org/10.1183/09031936.00041609

[22] Liu, Q., Dan, L., Haase, J.E., Guo, Q.H., Wang, X.Q., Liu, S., et al. (2020) The Experiences of Health-Care Providers during the COVID-19 Crisis in China: A Qualitative Study. Lancet Global Health, 8, 790-798. https://doi.org/10.1016/S2214-109X(20)30204-7

[23] Chang, D., Xu, H., Rebaza, A., Sharma, L. and Dela Cruz, C.S. (2020) Protecting Health-Care Workers from Subclinical Coronavirus Infection. The Lancet Respiratory Medicine, 8, e13. https://doi.org/10.1016/S2213-2600(20)30066-7

[24] Hopman, J., Allegranzi, B. and Mehtar, S. (2020) Managing COVID-19 in Low and Middle-Income Countries. JAMA, 323, 1549-1550. https://doi.org/10.1001/jama.2020.4169

[25] Xie, J., Tong, Z., Guan, X., et al. (2020) Critical Care Crisis and Some Recommendations during the COVID-19 Epidemic in China. Intensive Care Medicine, 46, 837-840. https://doi.org/10.1007/s00134-020-05979-7

[26] WHO (2020) Infection Prevention and Control Guidance for Long-Term Care Facilities in the Context of COVID-19. World Health Organization, Interim Guidance.

https://apps.who.int/iris/bitstream/handle/10665/331508/WHO-2019-nCoV-IPC lo ng term care-2020.1-eng.pdf

[27] American Psychiatric Nurses Association. https://www.bmj.com/content/368/bmj.m1211

[28] Dutra, H.S., Cimiotti, J.P. and Guirardello, E.D.B. (2018) Nurse Work Environment and Job Related Outcomes in Brazilian Hospitals. Applied Nursing Research, 41, 68-72. https://doi.org/10.1016/j.apnr.2018.04.002

[29] Kang, H.S., Son, Y.D., Chae, S.M. and Corte, C. (2018) Working Experiences of Nurses during the Middle East Respiratory Syndrome Outbreak. International Journal of Nursing Practice, 24, e12664.

[30] Bukhari, E.E., Temsah, M.H., Aleyadhy, A.A., Alrabiaa, A.A., Alhboob, A.A., Jamal, A.A. and Binsaeed, A.A. (2016) Middle East Respiratory Syndrome Coronavirus (MERS-CoV) Outbreak Perceptions of Risk and Stress Evaluation in Nurses. Journal of Infection in Developing Countries, 10, 845-850.

https://doi.org/10.3855/jidc.6925

[31] Chou, T.L., Ho, L.Y., Wang, K.Y., Kao, C.W., Yang, M.H. and Fan, P.L. (2010) Uniformed Service Nurses' Experiences with the Severe Acute Respiratory Syndrome Outbreak and Response in Taiwan. Nursing Clinics of North America, 45, 179-191. https://doi.org/10.1016/j.cnur.2010.02.008

[32] Corley, A., Hammond, N.E. and Fraser, J.F. (2010) The Experiences of Health Care Workers Employed in an Australian Intensive Care Unit during the H1N1 Influenza Pandemic of 2009: A Phenomenological Study. International Journal of Nursing Studies, 47, 577-585. https://doi.org/10.1016/j.ijnurstu.2009.11.015

[33] Koh, Y., Hegney, D. and Drury, V. (2012) Nurses' Perceptions of Risk from Emerging Respiratory Infectious Diseases: A Singapore Study. International Journal of Nursing Practice, 18, 195-204. https://doi.org/10.1111/j.1440-172X.2012.02018.x

[34] Cui, S.S., Jiang, Y.Y., Shi, Q.Y., Zhang, L., Kong, D.H., Qian, M.J. and Chu, J. (2020) Impact of COVID-19 on Psychology of Nurses Working in the Emergency and 
Fever Outpatient: A Cross-Sectional Survey. BMC Psychiatry. https://doi.org/10.21203/rs.3.rs-20777/v1

[35] Nickell, L.A. (2004) Psychosocial Effects of SARS on Hospital Staff: Survey of a Large Tertiary Care Institution. Canadian Medical Association Journal, 170, 793 798. https://doi.org/10.1503/cmaj.1031077

[36] Maunder, R. (2004) The Experience of the 2003 SARS Outbreak as a Traumatic Stress among Frontline Healthcare Workers in Toronto: Lessons Learned. Philosophical Transactions of the Royal Society of London. Series B, 359, 1117-1125. https://doi.org/10.1098/rstb.2004.1483

[37] Sabah, D. (2020) Coronavirus-Infected Italian Nurse Commits Suicide from Fear of Spreading COVID-19 to Patients.

https://www.dailysabah.com/world/europe/coronavirus-infected-italian-nurse-com mits-suicide-from-fear-of-spreading-covid-19-to-patients

[38] Xiao, J., Fang, M., Chen, Q. and He, B.X. (2020) SARS, MERS and COVID-19 among Healthcare Workers: A Narrative Review. Journal of Infection and Public Health, 13, 843-848. https://doi.org/10.1016/j.jiph.2020.05.019

[39] Li, J.H., Xu, J.D., Zhou, H., You, H., Wang, X.H, Li, Y., et al. (2020) Working Condition and Health Status of 6,317 Front Line Public Health Workers during the COVID-19 Epidemic Across 5 Provinces in China: A Cross-Sectional Study. https://www.who.int/bulletin/online first/20-255471.pdf https://doi.org/10.2471/BLT.20.255471

[40] Lai, J.B., Ma, S.M., Wang, Y., Cai, Z.X., Hu, J.B., Wei, N., et al. (2020) Factors Associated with Mental Health Outcomes among Health Care Workers Exposed to Coronavirus Disease 2019. JAMA Network Open, 3, e203976. https://doi.org/10.1001/jamanetworkopen.2020.3976

[41] Shultz, J.M., Baingana, F. and Neria, Y. (2015) The 2014 Ebola Outbreak and Mental Health: Current Status and Recommended Response. JAMA, 313, 567-568. https://doi.org/10.1001/jama.2014.17934

[42] Liu, S., Yang, L.L., Zhang, C.X., Xiang, Y.T., Liu, Z.C., Hu, S.H. And Zhang, B. (2020) Online Mental Health Services in China during the COVID-19 Outbreak. The Lancet Psychiatry, 7, e17-e18. https://doi.org/10.1016/S2215-0366(20)30077-8

[43] Jiang, Y. (2020) Psychological Impact and Coping Strategies of Frontline Medical Staff in Hunan between January and March 2020 during the Outbreak of Coronavirus Disease 2019 (COVID-19) in Hubei, China. Medical Science Monitor, 26, e924171.

[44] Ruotsalainen, J.H., Verbeek, J.H., Marine, A. and Serrated, C. (2015) Preventing Occupational Stress in Healthcare Workers. Cochrane Database of Systematic Reviews, No. 4, CD002892. https://doi.org/10.1002/14651858.CD002892.pub5

[45] Chen, R., Chou, K.R., Huang, Y.J, Wang, T.S., Liu, S.Y. and Ho, L.Y. (2006) Effects of a SARS Prevention Programme in Taiwan on Nursing Staff's Anxiety, Depression and Sleep Quality: A Longitudinal Survey. International Journal of Nursing Studies, 43, 215-225. https://doi.org/10.1016/j.ijnurstu.2005.03.006

[46] Dall'Ora, C., Griffiths, P., Redfern, O., Saucedo, A.R., Meredith, P., Ball, J., et al. (2019) Nurses' 12-Hour Shifts and Missed Or Delayed Vital Signs Observations on Hospital Wards: Retrospective Observational Study. BMJ Open, 9, e024778. https://doi.org/10.1136/bmjopen-2018-024778

[47] Stimpfel, A.W. and Aiken, L.H. (2013) Hospital Staff Nurses' Shift Length Associated with Safety and Quality of Care. Journal of Nursing Care Quality, 28, 122-129. https://doi.org/10.1097/NCQ.0b013e3182725f09 
[48] Griffiths, P., Dall'Ora, C., Simon, M., et al. (2014) Nurses' Shift Length and Overtime Working in 12 European Countries: The Association with Perceived Quality of Care and Patient Safety. Medicine Care, 52, 975-981. https://doi.org/10.1097/MLR.0000000000000233

[49] Rogers, A.E., Hwang, W.T, Scott, L.D., et al. (2004) The Working Hours of Hospital Staff Nurses and Patient Safety. Health Affairs, 23, 202-212. https://doi.org/10.1377/hlthaff.23.4.202

[50] Clendon, J. and Gibbons, V. (2015) 12 H Shifts and Rates of Error among Nurses: A Systematic Review. International Journal of Nursing Studies, 52, 1231-1242. https://doi.org/10.1016/j.ijnurstu.2015.03.011

[51] Trinkoff, A.M., Johantgen, M., Storr, C.L., et al. (2011) Nurses' Work Schedule Characteristics, Nurse Staffing, and Patient Mortality. Nursing Research, 60, 1-8 https://doi.org/10.1097/NNR.0b013e3181fff15d

[52] Ball, J., Day, T., Murrells, T., et al. (2017) Cross-Sectional Examination of the Association between Shift Length and Hospital Nurses Job Satisfaction and Nurse Reported Quality Measures. BMC Nursing, 16, Article No. 26.

https://doi.org/10.1186/s12912-017-0221-7

[53] Dall'Ora, C., Ball, J., Recio-Saucedo, A. and Griffiths, P. (2016) Characteristics of Shift Work and Their Impact on Employee Performance and Wellbeing: A Literature Review. International Journal of Nursing Studies, 57, 12-27. https://doi.org/10.1016/j.ijnurstu.2016.01.007

[54] Sagherian, K., Clinton, M.E. and Huijer, H.A.S. (2017) Fatigue, Work Schedules and Perceived Performance in Bedside Care Nurses. Workplace Health \& Safety, 65, 304-312. https://doi.org/10.1111/jocn.15307

[55] Olds, D.M. and Clarke, S.P. (2010) The Effect of Work Hours on Adverse Events and Errors in Health Care. Journal of Safety Research, 41, 153-162. https://doi.org/10.1111/jocn.15307

[56] Maben, J. and Bridges, J. (2020) Covid-19: Supporting Nurses' Psychological and Mental Health. Journal of Clinical Nursing, 29, 2742-2750.

[57] Kenrick, D.T., Griskevicius, V., Neuberg, S.L. and Schaller, M. (2010) Renovating the Pyramid of Needs: Contemporary Extensions Built upon Ancient Foundations. Perspectives on Psychological Science, 5, 292-314. https://doi.org/10.1177/1745691610369469

[58] Chen, J., Davis, K.G., Daraiseh, N.M., Pan, W. and Davis, L.S. (2014) Fatigue and Recovery in 12-Hour Dayshift Hospital Nurses. Journal of Nursing Management, 22, 593-603. https://doi.org/10.1111/jonm.12062

[59] Barker, L.M. and Nussbaum, M.A. (2011) Fatigue, Performance and the Work Environment: A Survey of Registered Nurses. Journal of Advanced Nursing, 67, 1370-1382. https://doi.org/10.1111/j.1365-2648.2010.05597.x

[60] Battisto, D., Pak, R., Vander Wood, M.A. and Pilcher, J.J. (2009) Using a Task Analysis to Describe Nursing Work in Acute Care Patient Environments. Journal of Nursing Administration, 39, 537-547. https://doi.org/10.1097/NNA.0b013e3181c1806d

[61] Kane, P.P. (2009) Stress Causing Psychosomatic Illness among Nurses. Indian Journal of Occupational \& Environmental Medicine, 13, 28-32. https://doi.org/10.4103/0019-5278.50721

[62] Chen, S.C., Lai, Y.H. and Tsay, S.L. (2020) Nursing Perspectives on the Impacts of COVID-19. The Journal of Nursing Research, 28, e85. https://doi.org/10.1097/NRJ.0000000000000389 
[63] Al-Enezi, B. Arab Times. https://arabtimesonline.com/news/new-mechanism-to-reduce-workload-for-somenurses/

[64] Baumgaertner, E. and Karlamangla, S. (2020) Doctors and Nurses Brace for Coronavirus Onslaught: "What Happens If I End up on a Ventilator?"

https://www.latimes.com/california/story/2020-03-20/coronavirus-doctors-nurses-f ears-ventilator-icu-emergency/

[65] Lam, K.K. and Hung, S.Y. (2013) Perceptions of Emergency Nurses during the Human Swine Influenza Outbreak: A Qualitative Study. International Emergency Nursing, 21, 240-246. https://doi.org/10.1016/j.ienj.2012.08.008

[66] Mohammed, A., Sheikh, T.L., Poggensee, G., Nguku, P., Olayinka, A., Ohuabunwo, C. and Eaton, J. (2015) Mental Health in Emergency Response: Lessons from Ebola. Lancet Psychiatry, 2, 955-957. https://doi.org/10.1016/S2215-0366(15)00451-4

[67] Law, T. (2020) We Carry That Burden.' Medical Workers Fighting COVID-19 Are Facing a Mental Health Crisis.

https://time.com/5817435/covid-19mentalhealthcoronavirus/

[68] Mishra, P., Bhadauria, U.S. and Dasar, P.L. (2016) Knowledge, Attitude and Anxiety towards Pandemic Flu a Potential Bio Weapon among Health Professionals in Indore City. Przegląd Epidemiologiczny, 70, 125-127.

[69] Main, A., Zhou, Q., Ma, Y., Luecken, L.J. and Liu, X. (2011) Relations of SARS-Related Stressors and Coping to Chinese College Students' Psychological Adjustment during the 2003 Beijing SARS Epidemic. Journal of Counseling Psychology, 58, 410-423. https://doi.org/10.1037/a0023632

[70] Kilmarx, P.H., Clarke, K.R., Dietz, P.M., et al. (2014) Ebola Virus Disease in Health Care Workers-Sierra Leone, 2014. Morbidity and Mortality Weekly Reports, 63, 1168-1171. https://www.cdc.gov/mmwr/pdf/wk/mm6349.pdf

[71] Lautenbach, E., Saint, S., Henderson, D.K. and Harris, A.D. (2010) Initial Response of Health Care Institutions to Emergence of H1N1 Influenza: Experiences, Obstacles, and Perceived Future Needs. Clinical Infectious Diseases, 50, 523-527. https://doi.org/10.1086/650169

[72] Rebmann, T., Wilson, R., LaPointe, S., Russell, B. and Moroz, D. (2009) Hospital Infectious Disease Emergency Preparedness: A 2007 Survey of Infection Control Professionals. American Journal of Infection Control, 37, 1-8. https://doi.org/10.1016/j.ajic.2008.02.007

[73] Kim, Y. (2018) Nurses' Experiences of Care for Patients with Middle East Respiratory Syndrome-Corona Virus in South Korea. American Journal of Infection Control, 46, 781-787. https://doi.org/10.1016/j.ajic.2018.01.012

[74] O’Boyle, C., Robertson, C. and Secor-Turner, M. (2006) Nurses' Beliefs about Public Health Emergencies: Fear of Abandonment. American Journal of Infection Control, 34, 351-357. https://doi.org/10.1016/j.ajic.2006.01.012

[75] Grasselli, G., Pesenti, A. and Cecconi, M. (2020) Critical Care Utilization for the COVID-19 Outbreak in Lombardo, Italy: Early Experience and Forecast during an Emergency Response. JAMA, 323, 1545-1546.

https://doi.org/10.1001/jama.2020.4031 